\title{
Surface Modification of Nanoclay for the Synthesis of Polycaprolactone (PCL) - Clay Nanocomposite
}

\author{
Kamal Yusoh ${ }^{1, *}$, Shamini Vesaya Kumaran ${ }^{1}$, and Fadwa Sameeha Ismail ${ }^{1}$ \\ ${ }^{1}$ Faculty of Chemical and Natural Resources Engineering, Universiti Malaysia Pahang, 26300 Gambang, Pahang Malaysia
}

\begin{abstract}
This paper presents a new modification method to modify the surface of nanoclay (NaMMT) to increase its $d$-spacing using Aminopropylisooctyl Polyhedral Oligomeric Silsesquioxane (AP-POSS) and the fabrication of Polycaprolactone (PCL) nanocomposite through solution intercalation technique. The structure and morphology of pure nanoclay, modified nanoclay (POSSMMT) and the PCL nanocomposite were characterized by X-ray Diffraction (XRD), Fourier Transform Infrared Spectroscopy (FTIR) and Field Emission Scanning Electron Microscopy (FESEM). XRD revealed that the $d$-spacing of the POSS-MMT is increased by $0.64 \mathrm{~nm}$ as compared to pure nanoclay. FTIR and FESEM results also showed that AP-POSS were well dispersed and intercalated throughout the interlayer space of Na-MMT. An exfoliated structure was also observed for PCL/POSS-MMT nanocomposite. Thermal properties of the nanocomposite were investigated using Thermal Gravimetry Analysis (TGA) which recorded highest degradation temperature for PCL/POSS-MMT $1 \%$ nanocomposite which is $394.1^{\circ} \mathrm{C}$ at $50 \%$ weight loss $\left(\mathrm{T}_{50} \%\right)$ but a decrease in degradation temperature when POSS-MMT content is increased and Differential Scanning Calorimetry (DSC) analysis which showed highest melting and crystallization temperature for PCL/POSS-MMT $5 \%$ nanocomposite which is $56.6^{\circ} \mathrm{C}$ and $32.7^{\circ} \mathrm{C}$ respectively whereas a decrease in degree of crystallinity for PCL/POSS-MMT nanocomposite as compared to PCL/Na-MMT nanocomposite. This study affords an efficient modification method to obtain organoclay with larger interlayer $d$-spacing to enhance the properties of polymer nanocomposite.
\end{abstract}

\section{Introduction}

Plastics are ideal for many applications such as in packaging, building materials and commodities but it can lead to waste disposal problems. Accumulation of plastic at the end of its life cycle had increased drastically on the earth causing serious pollution problems. Therefore, this motivated many researchers to conduct studies to produce a biodegradable and environmental friendly polymer nanocomposite to produce plastics. There has been a strong emphasis in the development of polymer nanocomposites for the last 20 years. Polymer nanocomposites consist of inorganic nanofiller and organic polymers represent a new class of materials that exhibit improved performance compared to their microcomposite counterparts [1].

Polycaprolactone (PCL) is considered to be a good biodegradable polymer because of the low production cost and easy processibility in large scale production. PCL have good commercial potential for plastics but their low thermal and mechanical properties for further processing restrict their use in a wide range of applications [2]. Therefore, these properties can be improved through the preparation of PCL nanocomposite by incorporating nanofiller such as nanoclay.
Sodium montmorillonite (Na-MMT) is the most abundant nanoclay mineral that is easily available with a good swelling capacity, high cation exchange capacity and high surface area [3]. However, the hydrophilic nature of nanoclay hinders homogenous dispersion of nanoclay in the hydrophobic polymer matrix [4]. Modifying the nanoclay surface through organic treatment will give a hydrophobic environment to the galleries of the Na-MMT and enhance its compatibility with the polymer matrix. Conventional modification method is the ion-exchange reaction using cationic salts such as alkyl ammonium or phosphonium salts. There are some drawbacks in this modification process such as low thermal stability of the cationic salts and the compounds are less readily intercalated in the polymer melts. Alkyl ammonium salt will decompose at temperature above $170-180^{\circ} \mathrm{C}$ which shows that it is not suitable for the high temperature melt processing techniques [5].

Thus, a new modification method will be the main aim of this study. The surfactant method by using Aminopropylisooctyl Polyhedral Oligomeric Silsesquioxane (AP-POSS) is developed to give a better surface modification for the Na-MMT. The main

\footnotetext{
*Corresponding author: kamal@ump.edu.my
} 
purpose of the surface modification of Na-MMT is to expand the interlayer $d$-spacing of the nanoclay gallery so that polymer molecules can penetrate as well as to enhance its miscibility with polymer to achieve a good dispersion. AP-POSS has a high thermal stability which is up to $300^{\circ} \mathrm{C}$. Therefore, an enhanced PCL nanocomposite can be produced with modified nanoclay.

Polymer nanocomposites usually can be prepared by using three different techniques such as in-situ polymerisation, melt blending and solution intercalation. Solution intercalation method is considered in this study because only a small amount of polymer nanocomposite is to be fabricated in a laboratory scale whereas the other two techniques is preferred for industrial scale. Thus, the main aim of this study is to develop a new modification method for dispersing nanofillers in PCL nanocomposite and to fabricate PCL nanocomposite through solution intercalation technique.

\section{Experimental}

\subsection{Materials}

Sodium montmorillonite (Na-MMT) was purchased from Southern Clays, Texas, US. The organic modifier, Aminopropylisooctyl Polyhedral Oligomeric Silsesquioxane (AP-POSS) was purchased from Hybrid Plastic Co., USA. Polycaprolactone (PCL), ethanol, acetic acid and chloroform were purchased from Fisher Scientific.

\subsection{Modification of Na-MMT using Surfactant Method}

Five (5) $\mathrm{g}$ of Na-MMT was suspended in $250 \mathrm{ml}$ of deionised water at $25^{\circ} \mathrm{C}$ with stirring for 2 hours. $2.332 \mathrm{~g}$ of AP-POSS was dissolved in $6 \mathrm{ml}$ of ethanol and acidified with $4 \mathrm{ml}$ of acetic acid. It is then added dropwise to the Na-MMT suspension over a period of 20 min [6]. The mixed suspension was then continuously stirred at $70^{\circ} \mathrm{C}$ for 24 hours to obtain the organoclay (POSS-MMT). Then the organoclay was harvested by centrifuge, dried in oven for 48 hours and ground to pass mesh sieve.

\subsection{Fabrication of PCL Nanocomposite}

The nanoclay $(1 \mathrm{wt} \%, 3 \mathrm{wt} \%$ and $5 \mathrm{wt} \%)$ was stirred in chloroform for $1 \frac{1}{2}$ hours. PCL (1g) was also stirred with chloroform $(20 \mathrm{ml})$ to get a solution of PCL/Chloroform. That solution was then dropped into nanoclay/chloroform suspension and stirred for $4 \frac{1}{2}$ hours. The suspension was poured into a clean petri dish and left covered for 2 days. After 2 days, the film was dried in a vacuum oven for 24 hours at $40^{\circ} \mathrm{C}$ to remove the residual traces of chloroform.

\subsection{Fabrication of PCL Nanocomposite}

XRD data was recorded on a MiniFlex Rigaku using graphite-filtered $\mathrm{Cu}-\mathrm{K} \alpha$ radiation $(1.25,0.154 \mathrm{~nm})$. The diffractometer was controlled using Diffrac Plus XRD Commander and the raw data was manipulated using EVA software [6]. All the data were collected between the ranges of $3^{\circ}$ to $80^{\circ} 2 \theta$ with a resolution of $0.02^{\circ}$. The $d$-spacing of the nanoclay were calculated by using the Bragg's law.

$$
\operatorname{Sin} \theta=n \lambda / 2 d
$$

Where, $d$ is the spacing between the layers of the nanoclay, $\lambda$ is the wavelength of the X-Ray which is $0.154 \mathrm{~nm}, \theta$ is the angle at the maximum point of the first peak in the spectra, $\mathrm{n}$ is the order of diffraction which 1.

FTIR was recorded by using Nicolet Omnic 3 FTIR spectrophotometer. The samples were used in the solid form. The background of the samples was in $\mathrm{KBr}$ standard. After the background is completed, the reading for the samples was collected.

FESEM analysis was done by using the JEOL FESEM JSM-7100F. 'Smart FESEM User Interface' program was run. The samples were mounted on the universal holder with stub forceps. The focus knob was turned to sharp the scanned images. FESEM images then were saved.

\subsection{Thermal Analysis of PCL nanocomposite}

TGA analysis was carried out by using Perkin Elmer TGA Q500. The samples were heated from $25^{\circ} \mathrm{C}$ to $600^{\circ} \mathrm{C}$ at a heating rate of $5^{\circ} \mathrm{C} / \mathrm{min}$ under nitrogen atmosphere. A mass change versus temperature curve was obtained.

DSC analysis was done using Perkin Elmer DSC Q1000 under nitrogen atmosphere. Measurement was performed from room temperature to $160^{\circ} \mathrm{C}$ at heating rate of $10^{\circ} \mathrm{C} / \mathrm{min}$. The samples were stand stilled for 5 minutes to erase any previous thermal history. Subsequent cooling and heating cycles was recorded respectively. The degree of crystallinity $\left(X_{\mathrm{cr}}\right)$ of the sample was calculated by using equation shown below.

$$
X_{c r}(\%)=\left(\Delta H_{f}\right) /\left(W_{P C L} \times \Delta H_{100}\right) \times 100 \%
$$

$\Delta \mathrm{H}_{100}$ represents heat of fusion of $100 \%$ crystalline PCL [136.1 J/g [7]], $\Delta \mathrm{H}_{\mathrm{f}}$ represents experimental heat of fusion and $\mathrm{W}_{\mathrm{PCL}}$ represents weight fraction of PCL.

\section{Results and Discussion}

\subsection{Characterization of Nanoclay}

X-ray Diffraction (XRD) analysis was used to characterize the interlayer $d$-spacing of the nanoclay galleries and the dispersion of nanoclay in the polymer nanocomposite structure. The pure nanoclay, Na-MMT shows the first characteristic peak at $2 \theta=14.9^{\circ}$ and the modified nanoclay, POSS-MMT shows at $2 \theta=7.16^{\circ}$ as indicated in the Figure 1. It can be clearly observed that 
there is a shift of characteristic reflections to lower angle in POSS-MMT compared to Na-MMT. The $d$-spacing of the nanoclays were calculated by using EQN 1. The $d$ spacing of the nanoclays increased from $0.593 \mathrm{~nm}$ for Na-MMT to $1.233 \mathrm{~nm}$ for POSS-MMT. This proved that the AP-POSS surfactant was successfully intercalated into the nanoclay galleries consequently pushing the nanoclay layers and confirms that modification process has taken place. Thus, this result corresponds to the study conducted by Zhao et al. (2009) [8] where the $d$ spacing increased from $0.96 \mathrm{~nm}$ for Na-MMT to $1.25 \mathrm{~nm}$ for POSS-MMT. This intercalation is an efficient way to increase the material surface hydrophobicity of $\mathrm{Na}$ MMT which is a fundamental requirement for good compatibility between the polymer matrix and the $\mathrm{Na}$ MMT surface [9]. Surfactant method gives a better increase in the $d$-spacing of the nanoclay compared to ion exchange reaction by alkyl ammonium salts where in the studies conducted by Uhl et al. (2004) [10], cetyltrimethylammonium bromide (CTMA) increases the nanoclay galleries only by $0.5 \mathrm{~nm}$ while the surfactant method used in this study could increase the nanoclay layer by $0.64 \mathrm{~nm}$.

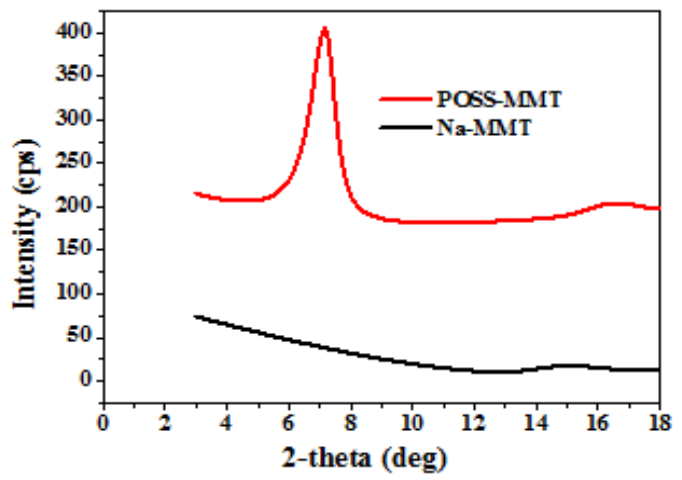

Fig. 1. XRD Spectra for Na-MMT and POSS-MMT

Fourier Transform Infrared Spectroscopy (FTIR) was used to analyse the presence of certain functional group in a molecule. In Figure 2, Na-MMT shows characteristic peak at $3630.97 \mathrm{~cm}^{-1}$ which represents the hydroxyl stretching vibration of $\mathrm{OH}$ group and at $3460.63 \mathrm{~cm}^{-1}$ which represents the broad band of stretching vibration of the interlayer water. Na-MMT also exhibits strong peaks at $1045.79 \mathrm{~cm}^{-1}$ for the Si-O stretching vibration, $523.87 \mathrm{~cm}^{-1}$ for the Al-O-Si deformation and $466.81 \mathrm{~cm}^{-1}$ for Si-O-Si deformation bonds [11]. The H-O-H bending vibration band can be observed at $1639.14 \mathrm{~cm}^{-1}$. All these bands are also present in POSS-MMT. The AP-POSS surfactant exhibits characteristics absorption peak for its aliphatic C-H stretching vibration from $\mathrm{CH}_{2}$ groups at 3000-2800 $\mathrm{cm}^{-1}$. The stretching vibration of N-H bond also might be present in the same band. AP-POSS also shows a peak at $1226.37 \mathrm{~cm}^{-1}$ for Si-C bond [12]. The symmetrical Si-O$\mathrm{Si}$ bond in the silsesquioxane cage is at stretching band of $1092.76 \mathrm{~cm}^{-1}$ [12]. All these bands also can be observed in the POSS-MMT which indicates the intercalation of AP-POSS surfactant into the nanoclay galleries. After the intercalation of AP-POSS surfactant, POSS-MMT not only had the characteristic bands of NaMMT but also exhibited the characteristic bands of APPOSS surfactant.

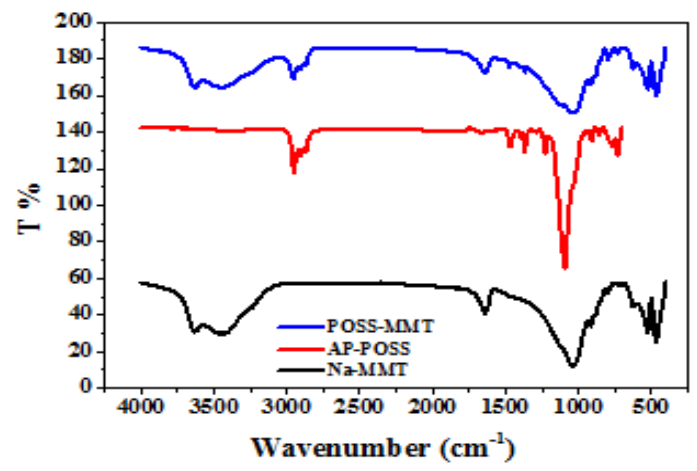

Fig. 2. FTIR Spectra for Na-MMT, AP POSS and POSS-MMT

The morphology of Na-MMT and POSS-MMT were analysed by means of FESEM. Figure 3 shows the FESEM images for both the nanoclays. In Figure 3 (a), the Na-MMT shows aggregated and curved plates. It also has a number of flakes with severely crumpled structure. In Figure 3 (b), POSS-MMT shows a finer and uniform morphology. The aggregated, curved and crumpled structure of the Na-MMT disappears and well dispersed particles obtained after modification. Finer and more uniform morphology is obtained in the modified nanoclay. This result is speculated might be because of the well intercalated nanoclay galleries with increased $d$ spacing which are due to the modification by using APPOSS.

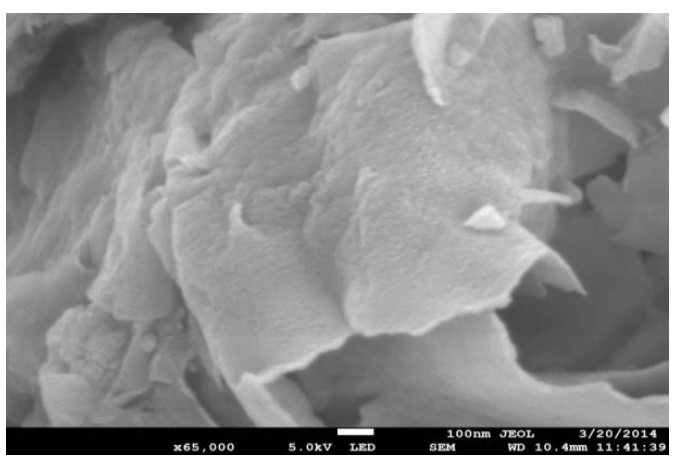

3(a)

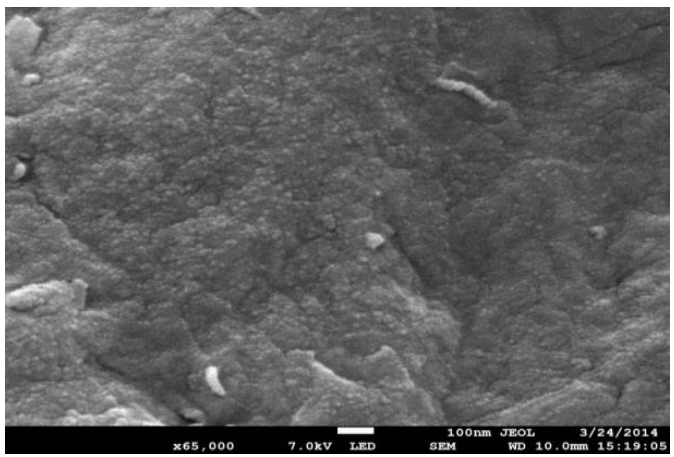

$3(b)$

Fig. 3. FESEM images of nanoclay (a) Na-MMT and (b) POSS-MMT 


\subsection{Characterization of PCL Nanocomposites}

XRD traces for the POSS-MMT and PCL/POSS-MMT nanocomposite is shown in Figure 4. The POSS-MMT has a characteristic peak at $2 \theta$ of $7.16^{\circ}$, corresponding to interlayer $d$-spacing of $1.233 \mathrm{~nm}$. There are no visible peaks for PCL/POSS-MMT nanocomposite which validates the formation of an exfoliated structure in the nanocomposite. The octyl chains in AP-POSS will be in straight alignment position by pushing the nanoclay interlayer galleries after the modification and PCL chains enter into the interlayer galleries of the nanoclay. This occurrence might have caused the destruction of the ordered geometry of nanoclay and resulting in complete delamination of the nanoclay layer on PCL matrix and forms an exfoliated structure. Similar observation has been reported by Liu et al. (2005) [13] where epoxy nanocomposite fabricated with POSS-modifed MMT does not exhibit any diffraction peaks in the XRD pattern representing exfoliated structure.

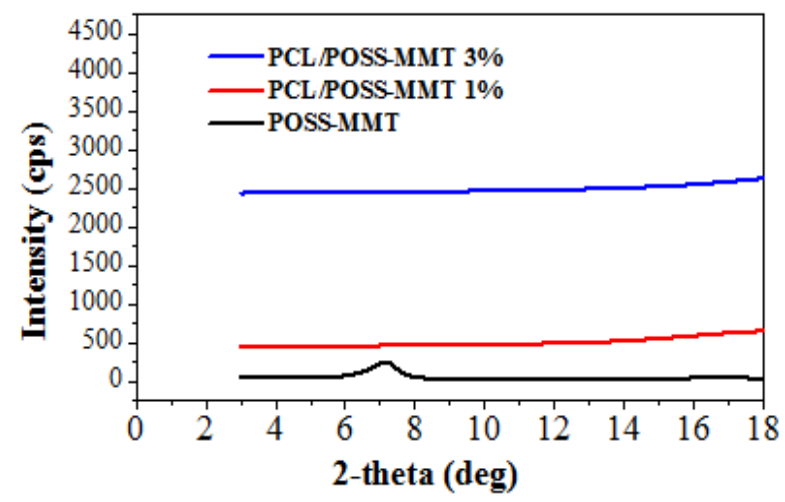

Fig. 4. XRD Pattern for POSS-MMT and PCL/POSS-MMT Nanocomposite

The FTIR spectra for pure PCL and PCL nanocomposite samples are shown in Figure 5. The pure PCL have peaks located at $2930-2945 \mathrm{~cm}^{-1}$ representing $\mathrm{CH}_{2}$ bonds stretching vibration. The vibration of $\mathrm{C}=\mathrm{O}$ bonds present at $1724 \mathrm{~cm}^{-1}$ band. The region of $1275 \mathrm{~cm}^{-1}$ to $1050 \mathrm{~cm}^{-1}$ indicates the $\mathrm{C}-\mathrm{O}-\mathrm{C}$ aliphatic ether stretching vibrations. All these important characteristic bands are situated in each PCL nanocomposite structure and show the presence of PCL. A new characteristic peak can be observed at the region of $3470-3485 \mathrm{~cm}^{-1}$ in the entire PCL nanocomposites. These peaks represent the broad band of stretching vibration of the interlayer water in the Na-MMT silicate. This band shows a slight increase in its intensity correlated with the increasing nanoclay content in each nanocomposite samples [14]. The most intense characteristic bands for Na-MMT are located in the region $1050-990 \mathrm{~cm}^{-1}$ attests the $\mathrm{Si}-\mathrm{O}$ stretching vibrations. Unfortunately, those characteristic bands cannot be distinguished because PCL has multiple bands in the same IR spectral range [14]. The presence of important principal characteristic bands of POSS-MMT falls in the region between $3000 \mathrm{~cm}^{-1}$ to $2800 \mathrm{~cm}^{-1}$. These bands which represent the $\mathrm{CH}_{2}$ stretching vibration and the $\mathrm{N}-\mathrm{H}$ bonds are also present in the pure
PCL structure. It also can be seen a small increase in the intensity of that particular peaks with increasing POSSMMT content. This result clearly verifies that intercalation of PCL with both unmodified and modified nanoclay has occurred.

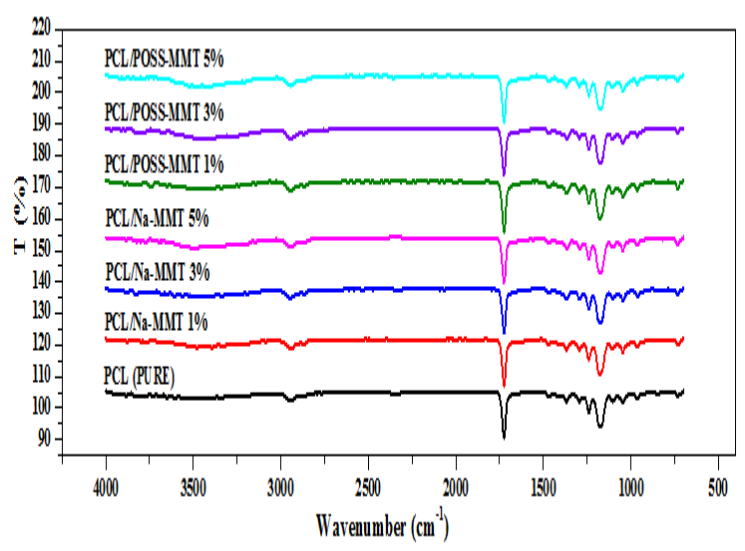

Fig. 5. FTIR Spectra of Pure PCL and PCL Nanocomposite

The FESEM analysis for PCL nanocomposite shows that POSS-treated nanoclay nanocomposite gives a matrix with well distributed particles compared to pure nanoclay nanocomposite as shown in Figure 6. In $\mathrm{PCL} / \mathrm{Na}-\mathrm{MMT}$ nanocomposite, nanoclay tends to stack together and do not disperse uniformly in the PCL matrices as shown in Figure 6(a). The Na-MMT tends to be agglomerated and stacked on the PCL matrix. This is because the immiscibility between Na-MMT and PCL is a major issue due to poor interfacial adhesion [15]. The distribution of modified nanoclay layers in PCL/POSSMMT nanocomposite appeared more uniform throughout the polymer matrix. The difference in morphology of PCL/Na-MMT $5 \%$ and PCL/POSSMMT 5\% nanocomposite is very obvious where the agglomerated particles disappear completely in $\mathrm{PCL} / \mathrm{POSS}-\mathrm{MMT} 5 \%$ nanocomposite as shown in Figure 6(b). This occurrence of finely dispersed modified nanoclay throughout the entire PCL matrix is because the compatibility of Na-MMT and PCL has been increased by modifying the Na-MMT.

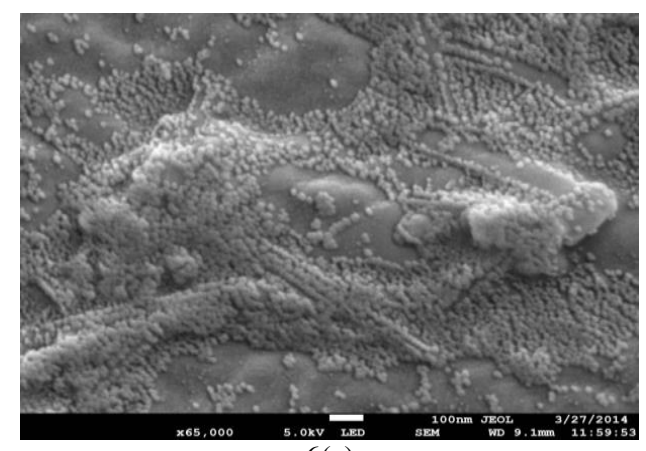

6(a) 


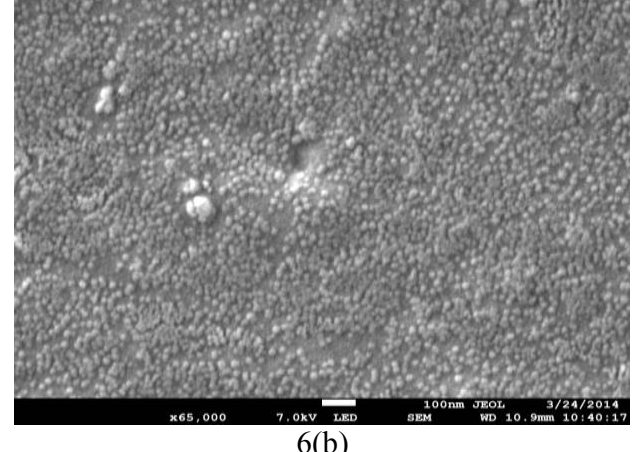

6(b)

Fig. 6. FESEM images for PCL nanocomposite (a) PCL/NaMMT (5\%) and PCL/POSS-MMT (5\%)

Thermal degradation of pure PCL and PCL nanocomposite was monitored through TGA. PCL materials degrade with a large peak in single step as observed for each sample in Figure 7. The degradation temperatures for $50 \%$ weight loss $\left(\mathbf{T}_{\mathbf{5 0} \%}\right)$ decreases gradually from $392.9^{\circ} \mathrm{C}$ for pure PCL to $391.4^{\circ} \mathrm{C}$ for PCL/Na-MMT 5\% nanocomposite and this is due to the incompatibility of Na-MMT with PCL matrix together with its hydrophilic character which can be related to the decomposition of physically adsorbed water and water molecules surrounding the exchangeable sites in $\mathrm{Na}$ MMT. A noticeable increase in degradation temperature at $\mathrm{T}_{50 \%}$ can be observed for PCL/POSS-MMT $1 \%$ nanocomposite which is $394.1^{\circ} \mathrm{C}$. The shift to higher degradation temperature is because POSS-MMT may act as a mass transport barrier to the volatile product that is generated during decomposition or diffusion hindrance of the decomposited volatiles through nanocomposite [16]. In a study conducted previously, the degradation temperature was higher for PCL/MMT- $\mathrm{C}_{8} \mathrm{H}_{17}$ nanocomposite and lower for PCL/Na-MMT nanocomposites compared to neat PCL at $\mathrm{T}_{50 \%}$ [16]. PCL/POSS-MMT 3\% and 5\% nanocomposite have the lowest degradation temperature among other samples which is $382.3^{\circ} \mathrm{C}$ and $364.8^{\circ} \mathrm{C}$ respectively. This can be associated with two major effects as the content of POSS-MMT increased. Firstly, the POSS-MMT could have functioned as an inorganic catalyst for polymer degradation [17]. Secondly, the AP-POSS surfactant can be decomposed at lower temperatures following the Hoffman elimination where these resulting degradation products of AP-POSS could have possibly contributed in catalyzing the degradation of PCL matrix [9]. The resistance to thermal degradation was improved when the organically modified nanoclay content is $1 \mathrm{wt} \%$ in PCL matrix but the effect levels off independently of the modified nanoclay beyond that content [16].Thus, the results obtained becomes obvious that the modified nanoclay may possess two opposing functions in thermal stability of polymer nanocomposites where it improves the thermal stability by barrier effect and decreases the thermal stability by catalytic effect on the degradation of the polymer matrix.

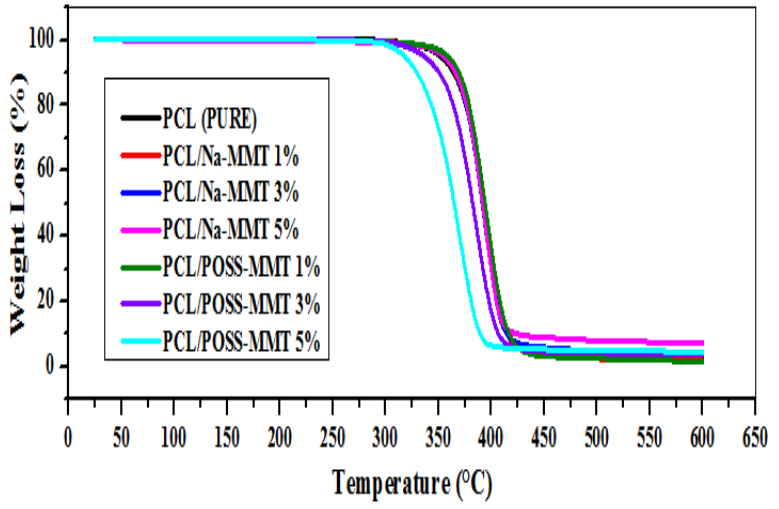

Fig. 7. TGA curves of Pure PCL and PCL Nanocomposite

The effect of nanoclay on the melting temperature $\left(\mathbf{T}_{\mathbf{m}}\right)$, crystallization temperature $\left(\mathbf{T}_{\mathbf{c}}\right)$ and degree of crystallinity $\left(\mathbf{X}_{\mathbf{c r}}\right)$ of PCL was analysed by DSC. Based on Table 1, it can be clearly seen that PCL/POSS-MMT nanocomposites possess a higher $\mathrm{T}_{\mathrm{m}}$ compared to PCL/Na-MMT nanocomposite loaded with equal amount of nanoclay and pure PCL where it shows $56.6^{\circ} \mathrm{C}$ for PCL/POSS-MMT 5\% nanocomposite. In the case of $\mathrm{T}_{\mathrm{c}}$, the PCL/Na-MMT nanocomposite experiences a decrease in the $\mathrm{T}_{\mathrm{c}}$ from pure PCL to PCL/Na-MMT 5\% nanocomposite which is from $31.9^{\circ} \mathrm{C}$ to $31.0^{\circ} \mathrm{C}$ then increases when POSS-MMT is incorporated into the PCL which is up to $32.7^{\circ} \mathrm{C}$ for PCL/POSS-MMT 5\% nanocomposite. Similar results were reported by Di et al. (2003) [18], where $T_{c}$ of the polymer matrix increased with the addition of a small amount of C30B, an organoclay to the PCL matrix. The increase in both these temperatures are because of increased order of lamellar crystals of PCL or the molecular mobility of PCL segments was suppressed by spatial confinement due to the presence of organoclay particles [19]. There also could be nano-reinforcement effect of Na-MMT layers together with the intercalating AP-POSS surfactant which were well dispersed in the PCL matrix. The $T_{m}$ and $\mathrm{T}_{\mathrm{c}}$ of nanocomposite depend on the degree of dispersion of nanoclay and its dispersed sizes in the polymer matrix. The PCL/Na-MMT nanocomposites have a higher $\mathrm{X}_{\mathrm{cr}}$ (calculated by equation 2 ) compared to the PCL/POSS-MMT nanocomposite with the same amount of nanoclay loading. The presence of surfactant at the interface can prevent the nucleation process and leads to decrease in the crystallinity [20]. The decrease in $\mathrm{X}_{\mathrm{cr}}$ is also due to the reduced mobility of the polymer chains in presence of strongly interacting nanoclay [18]. Thus, incorporation of modified nanoclay into PCL matrix improves the $T_{m}$ and $T_{c}$ compared to unmodified nanoclay but reduces the $\mathrm{X}_{\mathrm{cr}}$. 
Table 1. DSC Data for Pure PCL and PCL Nanocomposite

\begin{tabular}{cccc}
\hline Sample & $\begin{array}{c}\text { Melting } \\
\text { Temperatu } \\
\text { re }\left({ }^{\circ} \mathbf{C}\right)\end{array}$ & $\begin{array}{c}\text { Crystallizati } \\
\text { on } \\
\text { Temperature } \\
\left({ }^{\circ} \mathbf{C}\right)\end{array}$ & $\begin{array}{c}\text { Degree of } \\
\text { Crystallin } \\
\text { ity (\%) }\end{array}$ \\
\hline PCL (Pure) & 55.9 & 31.9 & 33.6 \\
PCL/Na-MMT & 56.4 & 31.5 & 40.9 \\
$\begin{array}{l}\text { 1\% } \\
\text { PCL/Na-MMT }\end{array}$ & 56.3 & 30.6 & 43.8 \\
$\begin{array}{c}\text { 3\% } \\
\text { PCL/Na-MMT }\end{array}$ & 56.3 & 31.0 & 40.2 \\
$\begin{array}{c}\text { 5\% } \\
\text { PCL/POSS-MMT }\end{array}$ & 56.5 & 31.8 & 37.3 \\
$\begin{array}{c}\text { 1\% } \\
\text { PCL/POSS-MMT }\end{array}$ & 56.4 & 32.2 & 37.2 \\
$\begin{array}{c}\text { 3\% } \\
\text { PCL/POSS-MMT }\end{array}$ & 56.6 & 32.7 & 35.8 \\
5\% & & & \\
\hline
\end{tabular}

\section{Conclusion}

The new AP-POSS based surfactant method for modification of nanoclay was done successfully where a significant increase in the interlayer $d$-spacing from $0.593 \mathrm{~nm}$ in Na-MMT to $1.233 \mathrm{~nm}$ in POSS-MMT has been achieved. The AP-POSS surfactant was successfully intercalated into the interlayer galleries of Na-MMT. The disappearance of diffraction peak in XRD for PCL/POSS-MMT nanocomposite and FESEM images verifies a good dispersion of POSS-MMT layers in the PCL matrix. TGA results showed highest degradation temperature of $394.1^{\circ} \mathrm{C}$ at $\mathrm{T}_{50 \%}$ for PCL/POSS-MMT 1\% nanocomposite. DSC data showed highest $\mathrm{T}_{\mathrm{m}}$ of $56.6^{\circ} \mathrm{C}$ and $\mathrm{T}_{\mathrm{c}}$ of $32.7^{\circ} \mathrm{C}$ for PCL/POSSMMT 5\% nanocomposite with a lower $\mathrm{X}_{\mathrm{cr}}$ of $35.8 \%$ as compared to PCL/Na-MMT nanocomposite. PCL/POSSMMT nanocomposite has enhanced thermal properties compared to pure PCL. Organic modification of nanoclay with new surfactant method gives good potential for incorporation with various biodegradable polymers such as Polybutylene Succinate and Polylactic Acid to give enhanced properties.

The authors gratefully acknowledge the financial supported by UMP under research funding RDU150398 and Ministry of Higher Education Malaysia under FRGS scheme RDU160149

\section{References}

1. Kango, S., Kalia, S., Celli, A., Njuguna, J., Habibi, Y., \& Kumar, R. (2013). Progress in Polymer Science, 38, 1232- 1261.

2. Sinha, R.S.S., \& Bousima, M. (2005). Prog. Mater. Sci., Vol. 50, 962-1079

3. Hossain, M. D., Kim, W. S., Hwang, H. S., \& Lim, K. T. (2009). Journal of Colloid and Interface Science, 336, 443-448.
4. Gorrasi, G., Tortora, M., Vittoria, V., Pollet, E., Lepoittevin, B. D., Alexandre, M., \& Dubois, P. (2003). Polymer, 44, 2271-2279.

5. Sarier, N., Onderb, E., \& Ersoyb, S. (2010). Colloids and Surfaces A: Physicochem. Eng. Aspects, 371, 40-49.

6. McLauchlin, A., Bao, X., \& Zhao, F. (2011). Applied Clay Science, 53, 749-753.

7. Yam, W. Y., Ismail, J., Kammer, H. W., Schmidt, H., \& Kummerlowe, C. (1999). Polymer 40, 5545-5552.

8. Zhao, F., Wan, C., Bao, X., \& Kandasubramanian, B. (2009). Journal of Colloid and Interface Science, 333, 164-170.

9. Achaby, M. E., Ennajih, H., Arrakhiz, F.Z., Kadib, A. E., Bouhfid, R., Essassi, E., \& Qaiss, A. (2013). Composites: Part B, 51, 310-317.

10. Uhl, F. M., Davuluri, S. P., Wong, S. C., \& Webster, D. C. (2004). Polymer, 45, 61756187.

11. Zhou, Q., Pramoda, K. P., Lee, J. M., Wanga, K., \& Loo, L. S. (2011). Journal of Colloid and Interface Science, 355, 222-230.

12. Fu, H. K., Kuo, S. W., Yeh, D. R., \& Chang, F. C. (2008). Journal of Nanomaterials, Article ID 739613, 7 pages.

13. Liu, H. Z., Zhang, W., \& Zheng, S. (2005). Polymer, 46, 157-65.

14. Viville, P., \& Lazzaroni, R. (2003). Langmuir, 19, 9425-9433.

15. Ahmed, J., Auras, R., Kijchavengkul, T., \& Varshney, S. K. (2012). Journal of Food Engineering, 111, 580-589.

16. Lepoittevin, B., Pantoustier, N., Alexander, M., Calberg, C., Jerome, R., \& Dubois, P. (2002). J Mater Chem, 12, 3528-32.

17. Qin, H., Zhang, S., Zhao, C., Feng, M., Yang, M., Shu, Z., et al. (2004). Polym Degrad Stabil, 85, 807-13.

18. Di, Y., Iannace, S., Maio, E. D., \& Nicolais, L. (2003). J Polym Sci Part B: Polym Phys, 41, 670-8.

19. Wu, T., Xie, T., \& Yang, G. (2009. Applied Clay Science, 45, 105-110.

20. Eleonora, E., Fernanda, M., Antonia, \& T.M., Hugo, D. (2011). Journals of Material Science and Engineering A, 778-789. 